\title{
Science council returns to political favour
}

Tokyo. One of Japan's leading brain researchers, Masao Ito, was elected last week as the new chairman of the Science Council of Japan, the government's main academic advisory body on science policy. Ito succeeds Jiro Kondo, who has headed the council for the past nine years. His appointment comes at a time of growing influence of the council on government policy.

The council has 210 members elected every three years by nearly a thousand registered scientific societies, including those in social science, engineering and medicine, and receives a small budget from the prime minister's office.

The council fell out of favour with the government in the 1970s and 1980s largely because it was seen as a "nest of communists" that always disagreed with government policy - it had opposed all forms of nuclear power, and repeatedly disagreed with the government on education policy.

At that time, all Japanese scientists had the right to elect members of the council. But voting fell prey to groups of socialists

and communists who, according to one council member, established a "systematic machine" to elect members with left-wing views. As a result, many senior academics shunned membership of the council.

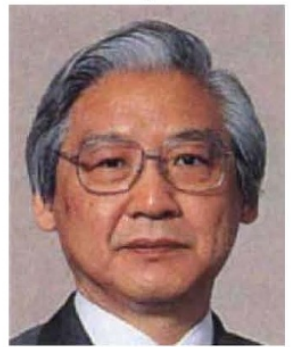

Ito: plans a more active role.
Voting procedures were changed in 1985 to give voting rights to scientific societies rather than individuals. Furthermore, even though only a formality, the prime minister now has to approve the appointment of all elected members.

Kondo took over leadership of the council in 1985 under the new regime, and has served three terms of three years each, during which time the council has returned to government favour, and now includes many of Japan's leading scientists.

Between 1989 and 1993, for example,

\section{Japan backs brain and AIDS research}

Tokyo. Research on the brain and on AIDS will receive the biggest single multi-year grants - each worth more than $¥ 1$ billion (US\$10 million) - in next year's 'priority' grants for large teams of researchers announced last week by Japan's Ministry of Education, Science and Culture.

In contrast, this year's 'special distinguished' grants, the ministry's largest grants for individuals which were also announced last week, are concentrated more on the physical sciences, in particular materials science and chemistry. Both type of awards indicate the areas where some of Japan's best basic research is being carried out.

The 23 multi-year priority grants begin next fiscal year which starts on 1 April, giving time for teams of researchers to be assembled. Yoshiyuki Nagai of Tokyo University's Institute of Medical Science will head one such team, which will investigate the pathogenesis and control of AIDS, and will be carried out at about 30 institutions throughout the country.

The team is expected to receive about $¥ 1.2$ billion over three years, but this may be cut back slightly by the Ministry of $\mathrm{Fi}$ nance. This marks a significant boost in the government's spending on AIDS research, at present only a few billion yen a year.

Two even larger grants go to brain research. Takao Shimizu of Tokyo University's faculty of medicine will head a team of about 50 researchers at a dozen institutions investigating molecular mechanisms of synaptic plasticity with a four-year grant expected to exceed $¥ 1.4$ billion. The other is to Tadaharu'Tsumoto of Osaka University's medical school, who will head a group spread among about 20 institutions that hopes to elucidate the functional development of neural circuits at the molecular level.

This follows a general trend by the government to increase support for brain research (see Nature 370, 243; 1994).

Research on advanced computer systems, including virtual reality and 'intelligent' silicon electronic systems, also gets significant support in the priority grants.

In contrast to the priority grants, the special distinguished grants, which provide a few million dollars to individuals for projects lasting between three and five years, take effect immediately. In the 1980s and early 1990 s, these grants were dominated by awards in biology. In the past few years, however, the emphasis has shifted to the physical sciences, which account for six of the 10 grants announced last week.

Ministry of Education officials say the shift is because applications from physical sciences have doubled in the past three years, whereas those from biological sciences have remained more or less constant. This reflects the strength of Japan in newly emerging areas of material science, such as high-temperature superconductors.

Outstanding among them is an award of $¥ 281$ million over four years to Akihisa Inoue of Tohoku University's Institute for Materials Research for research aimed at the discovery and development of new types of glass made out of metallic materials with glass-like properties. when Japan was faced with requests from the United States government to fund the Superconducting Super Collider, the prime minister and Japanese government repeatedly turned to the council for advice.

The government's new appreciation of the council was demonstrated last week when the prime minister, Tomiichi Murayama, invited all 210 members of the council to his residence for the first time.

Ito is a former dean of the medical faculty of Tokyo University and director-general of the Frontier Research Programme at the Institute of Physical and Chemical Research (RIKEN). He is well known internationally for his research on the brain, in particular on synaptic plasticity and the cerebellum, and as one of the architects of the International Human Frontier Science Programme, a foundation that supports research on the brain and biological functions.

Although the reputation and influence of the council has been re-established under Kondo's leadership, it still suffers from what some members call "Japan Science Council disease". This is the tendency for the council to send out questionnaires to the hundreds of thousands of scientists it represents on a particular topic, analyse the results, produce a report - and then forget it.

Ito has already indicated that he intends to give the council an even more active role in setting Japan's science policy than in the recent past. He is quoted in Monday's edition of Japan's leading financial newspaper, the Nikkei Shimbun, as saying "the council should not just carry out [the] routine work of the little brain (cerebellum), rather it has to do [the] creative work of the brain proper (cerebrum)".

David Swinbanks

\section{Russia takes steps to block brain-drain}

Moscow. The Russian government has adopted a new programme aimed at reducing the emigration of scientists to the West by paying them more to stay at home. Its approach is based primarily on broadening the system of hiring scientists on a contract, rather than a salaried, basis.

The government's decision followed a cabinet discussion in which Boris Saltykov, the minister for science, said that in 1992 alone, 4,500 scientists had left Russia. Overall, he said, the science sector had lost one quarter of its employees in 1993.

The main destinations of scientists leaving the country were the United States, France and Germany. The government has agreed to allocate an additional 42 billion roubles (US\$20 million) to attempt to stem the brain-drain and encourage scientists to remain in Russia. 